
Web of Science ${ }^{T}$

\section{Fabrication and Sintering Behavior of Zinc-Doped Biphasic Calcium Phosphate Bioceramics}

By: Sopyan, I (Sopyan, I.. ${ }^{[1]}$; Gunawan (Gunawan) ${ }^{[1,2]}$; Shah, QH (Shah, Q. H.) ${ }^{[3]} ;$ Mel, M (Mel, M.) $)^{[4]}$

\section{MATERIALS AND MANUFACTURING PROCESSES}

Volume: 31 Issue: 6 Pages: 713-718

DOI: $10.1080 / 10426914.2015 .1048361$

Published: APR 252016

View Journal Information

\begin{abstract}
Dense bioceramics with improved mechanical properties have been prepared using sol-gel derived zinc doped biphasic calcium phosphate (BCP) powders. Zinc concentration was varied in the range of 0,1 , $2,4,5,10$, and $15 \mathrm{~mol} \%$. The compaction of the powders followed by sintering provided the dense ceramics. The effects of zinc concentration doped and sintering temperature on phase stability and mechanical characteristics were examined. The presence of $\mathrm{Zn}$ changed the phase of dense BCP, leading to improved mechanical properties. $\mathrm{Zn}$ free BCP attained the highest density of only $92.6 \%$ after 1400 degrees $C$ sintering, equally achieved by $4 \mathrm{~mol} \% \mathrm{Zn}$-doped BCP at a lower temperature of 1200 degrees C. It is presumed that the steady increase in the compact density up to $4 \mathrm{~mol} \%$ zinc incorporation was contributed by progressive consolidation in the BCP structure, but the density dropped again from $5 \mathrm{~mol} \%$ until $15 \mathrm{~mol} \%$ due to low density beta-tricalcium phosphate phase formation. This study showed that $\mathrm{Zn}$ doping was effective in producing high strength dense BCP with 3.40GPa hardness and 1.43MPa center dot $\mathrm{m}(1 / 2)$ fracture toughness.
\end{abstract}

\section{Keywords}

Author Keywords: Zinc; Biphasic; Characterization; Mechanical; Biomaterials; Calcium phosphate; Dopant; Ceramics

KeyWords PIus: TRICALCIUM PHOSPHATE; BONE-FORMATION; IN-VITRO; HYDROXYAPATITE; CERAMICS; NANOPOWDERS; STABILITY; ZN

\section{Author Information}

Reprint Address: Sopyan, I (reprint author)

+ Int Islamic Univ Malaysia, Dept Mfg \& Mat Engn, Fac Engn, POB 10, Kuala Lumpur 50728, Malaysia.

Addresses:

+ [1] Int Islamic Univ Malaysia, Dept Mfg \& Mat Engn, Fac Engn, POB 10, Kuala Lumpur 50728, Malaysia

[ 2 ] Sriwijaya Univ, Dept Mech Engn, Fac Engn, Inderalaya, Indonesia

+ [ 3 ] Int Islamic Univ Malaysia, Dept Mech Engn, Fac Engn, Kuala Lumpur 50728, Malaysia

+ [ 4 ] Int Islamic Univ Malaysia, Dept Biotechnol, Fac Engn, Kuala Lumpur 50728, Malaysia

E-mail Addresses: sopyan@iium.edu.my

\section{Publisher}

TAYLOR \& FRANCIS INC, 530 WALNUT STREET, STE 850, PHILADELPHIA, PA 19106 USA

\section{Citation Network}

0 Times Cited

25 Cited References

View Related Records

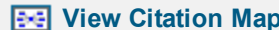

Create Citation Alert

(data from Web of Science ${ }^{T M}$ Core Collection)

\section{All Times Cited Counts}

0 in All Databases

0 in Web of Science Core Collection

0 in BIOSIS Citation Index

0 in Chinese Science Citation

Database

0 in Data Citation Index

0 in Russian Science Citation Index

0 in SciELO Citation Index

\section{Usage Count}

Last 180 Days: 3

Since 2013: 3

Learn more

This record is from:

Web of Science ${ }^{\mathrm{TM}}$ Core Collection

Suggest a correction

If you would like to improve the quality of the data in this record, please suggest a correction. 
Search

Back to results | 1 of 1

Full Text $\mid$ View at Publisher | 틀 Export | 분 Download | 4 Add to List | More... -

Materials and Manufacturing Processes

Volume 31, Issue 6, 25 April 2016, Pages 713-718

\section{Fabrication and Sintering Behavior of Zinc-Doped Biphasic Calcium Phosphate Bioceramics (Article)}

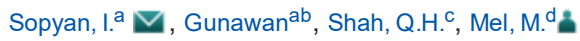

a Department of Manufacturing and Materials Engineering, Faculty of Engineering, International Islamic University Malaysia P.O.Box 10, Kuala Lumpur, Malaysia

b Department of Mechanical Engineering, Faculty of Engineering, Sriwijaya University, Inderalaya, Indonesia

c Department of Mechanical Engineering, Faculty of Engineering, International Islamic University Malaysia, Kuala Lumpur, Malaysia

$\boxplus$ View additional affiliations

\section{Abstract}

$\checkmark$ View references $(25)$

Dense bioceramics with improved mechanical properties have been prepared using sol-gel derived zinc doped biphasic calcium phosphate (BCP) powders. Zinc concentration was varied in the range of 0,1 , 2, 4, 5, 10, and $15 \mathrm{~mol} \%$. The compaction of the powders followed by sintering provided the dense ceramics. The effects of zinc concentration doped and sintering temperature on phase stability and mechanical characteristics were examined. The presence of $\mathrm{Zn}$ changed the phase of dense BCP, leading to improved mechanical properties. Zn free BCP attained the highest density of only $92.6 \%$ after $1400^{\circ} \mathrm{C}$ sintering, equally achieved by $4 \mathrm{~mol} \% \mathrm{Zn}$-doped BCP at a lower temperature of $1200^{\circ} \mathrm{C}$. It is presumed that the steady increase in the compact density up to $4 \mathrm{~mol} \%$ zinc incorporation was contributed by progressive consolidation in the BCP structure, but the density dropped again from 5 mol\% until $15 \mathrm{~mol} \%$ due to low density $\beta$-tricalcium phosphate phase formation. This study showed that $\mathrm{Zn}$ doping was effective in producing high strength dense BCP with $3.40 \mathrm{GPa}$ hardness and 1.43 $\mathrm{MPa} \cdot \mathrm{m}^{1 / 2}$ fracture toughness. Copyright (C) Taylor \& Francis Group, LLC.

\section{Author keywords}

Biomaterials; Biphasic; Calciumphosphate; Ceramics; Characterization; Dopant; Mechanical; Zinc

Indexed keywords

Engineering controlled terms: Bioceramics; Biomaterials; Calcium; Ceramic materials Characterization; Doping (additives); Fracture toughness; Mechanical properties; Powders; Sintering; Sols; Zinc

Beta tricalcium phosphate; Biphasic; Biphasic calcium phosphates; Ceramics; Mechanical; Mechanical characteristics; Sintering behaviors; Sintering temperatures

Engineering main heading: Calcium phosphate

ISSN: 10426914 CODEN: MMAPE Source Type: Journal Original language: English

DOI: 10.1080/10426914.2015.1048361 Document Type: Article

Publisher: Taylor and Francis Inc.

References (25)

View in search results format
Cited by 0 documents

Inform me when this document is cited in Scopus:

Set citation alert $\mid$ ถ Set citation feed

Related documents

Investigations of the effects of initial $\mathrm{Zn}$ concentration and sintering conditions on the phase behavior and mechanical properties of $\mathrm{Zn}$-doped bcp

Gunawan, Sopyan, I. , Mel, M.

(2014) Advances in Environmental Biology

Zinc-doped biphasic calcium phosphate nanopowders synthesized via sol-gel method Gunawan, Sopyan, I. , Suryant

(2014) Indian Journal of Chemistry - Section A Inorganic Physical, Theoretical and Analytical Chemistry

Substituted hydroxyapatites for biomedical applications: A review

Šupová, M.

(2015) Ceramics International

View all related documents based on references

Find more related documents in Scopus based on:

a Authors 9 Keywords

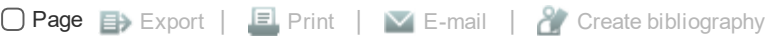

Dorozhkin, S.V.

1

Calcium orthophosphates as bioceramics state of the art 